\title{
Effect of P-EPQ as a secondary antioxidant on the properties of Biaxially Oriented Polypropylene film
}

\author{
Vishal Goel ${ }^{1}$, Suresh Mani ${ }^{2}$, Anil Yadav ${ }^{1}$, Jatinder Singh Dhaliwal ${ }^{1 *}$, Shashikant ${ }^{1}$ and Gurpreet \\ Singh Kapur ${ }^{1}$
}

\begin{abstract}
P-EPQ (Tetrakis(2,4-di-tert-butylphenyl)-4,4biphenyldiphosphonite) is a well-known phosphorus based secondary antioxidant used in Polyolefins for stabilization. P-EPQ has a low melting point and promotes good solubility in Polyolefins. It also helps in reduction of undesired colour during the processing. Biaxially Oriented Polypropylene (BOPP) film is a multilayer film, prepared at very high temperature and shear, and needs to be properly stabilized with primary and secondary antioxidant. Apart from the colour, other properties like dyne retention and compatibility with impact copolymers are also prime requisites of the BOPP. In this paper, a method was developed for analysis of P-EPQ using HPLC. Further, the effect of P-EPQ on dyne retention properties in BOPP films is discussed. A hypothesis for improvement in dyne retention has been proposed. Structural comparison of two different P-EPQ samples by HPLC was carried out and their effect on properties of BOPP film was studied.
\end{abstract}

\section{KEYWORDS}

P-EPQ, Biaxially Oriented Polypropylene (BOPP)

Film, antioxidants, Polypropylene, dyne

retention

\footnotetext{
${ }^{1}$ Indian Oil Corporation Ltd, R\&D Division, Faridabad, Haryana, India

${ }^{2}$ Indian Oil Corporation Ltd, Product Application and Development Centre, Panipat, Haryana, India

*Corresponding author; email singhj4@indianoil.in
}

\section{INTRODUCTION}

Polypropylene is being considered the perfect material for various applications, especially packaging, because of its various advantages over other polyolefin materials and its low cost and good thermal stability. Biaxially oriented films, especially based on polyolefins, represent a major component of the film packaging industry. Biaxially oriented polypropylene films are mostly produced through a sequential biaxial stretching process, in which films are cold drawn in two consecutive steps at two different temperatures (Philips et al., 2001; Dias et al., 2006; Lupke et al., 2004; Rettenberger et al., 2002).

Metallized biaxially oriented polypropylene (BOPP) films offer excellent gas and water vapor barrier and now are being extensively used in food packaging applications mainly in the form of multi-layer structure and also in general packaging or lamination of other materials. The Polypropylene being non-polar in nature has a low surface energy (Decker et al., 2002) and hence pre-treatment of the BOPP film is essential to have good adhesion with metal. There are methods of pre-treatment mentioned in the literature (Blythe et al., 2978; Markgraf MP 1993) like corona atmosphere or lowpressure plasma pre-treatment which provides surface functionality and thus proper adhesion.

To measure the surface functionality, Dyne value on the metalized side of BOPP film is measured and as a rule it should not drop very fast within the stipulated time (Markgraf DA, 1998) The dyne level is measured as a way of 
indicating the chemical cleanliness of the surface. There will be a dyne level that indicates that the surface is clean and a value of around 38 units is perceived acceptable by converters over a period of 6 months. Drop in dyne levels beyond this particular value can result in problem during metallization and lead to inferior optical properties.

Since the BOPP film production includes multiple steps of production and the film is prepared at a very high temperature and shear, it needs to be properly stabilized with primary and secondary antioxidant (Kenneth and Harrison, 2010). The main requirement of BOPP films is that a) it should not be yellowish, b) it should have optimum mechanical and optical properties, c) it should not break at high line speed, d) it should be able to retain the dyne value, e) it should have good compatibility with impact polypropylene in multilayer application. The trend towards using wider and faster production lines makes it necessary to develop effective stabilization that resist the stresses encountered during processing without loss of mechanical and optical properties. There are many secondary antioxidants (Krohnke and Werner 2001, Tolinski M 2009) available in the market, sold by trade names like Irgafos 168 , P$E P Q$, Ultranox 626 etc. PEP-Q is not a single compound and is comprised of a mixture of various compounds including its isomers.

The objective of this paper was to showcase the difference in properties of BOPP films containing different secondary antioxidants. Also, how the secondary antioxidant, particularly $\mathrm{P}$-EPQ, improves the surface properties of the BOPP film. In addition, an HPLC method was developed to separate various components of $\mathrm{P}-\mathrm{EPQ}$. Moreover, $\mathrm{P}-\mathrm{EPQ}$ from two different sources was obtained and characterized by HPLC and difference in composition was highlighted.

\section{RESULTS AND DISCUSSION \\ Characterization of P-EPQ from different sources \\ $P-E P Q$ is not single component and is mixture of} many components (Bruheim et al, 20). Table 3.1 summarizes different components present along with their typical concentration in P-EPQ.

\begin{tabular}{lll}
\hline S. No & Components & Composition (\%) \\
\hline 1 & $4,4^{\prime}-\mathrm{PEPQ}$ & $36-46$ \\
2 & $4,3^{\prime}-\mathrm{PEPQ}$ & $17-23$ \\
3 & $3,3^{\prime}-\mathrm{PEPQ}$ & $2-5$ \\
4 & Oxidized P-EPQ & $2-5$ \\
5 & Mono-P-EPQ & $11-19$ \\
6 & Irgafos 168 & $9-18$ \\
\hline
\end{tabular}

Table 3.1 Composition of P-EPQ

Major component present in P-EPQ is 4,4'$P E P Q$, Irgafos 168 content in P-EPQ varies from 9-18\%. P-EPQ1 and P-EPQ2 available from two different commercial sources were characterized by liquid chromatography. Figure 3.2 shows that number of components present in P-EPQ1 and P-EPQ2 are similar but their concentration varies. Since standards of different components of P-EPQ were not available; hence it was not possible to assign the individual component in the HPLC chromatogram. Only Irgafos 168 was available and in HPLC chromatogram it is marked as component 4 . A comparison of area counts of $P$ EPQ1 and P-EPQ2 sample at same concentration level was done and is presented in Table 3.2 


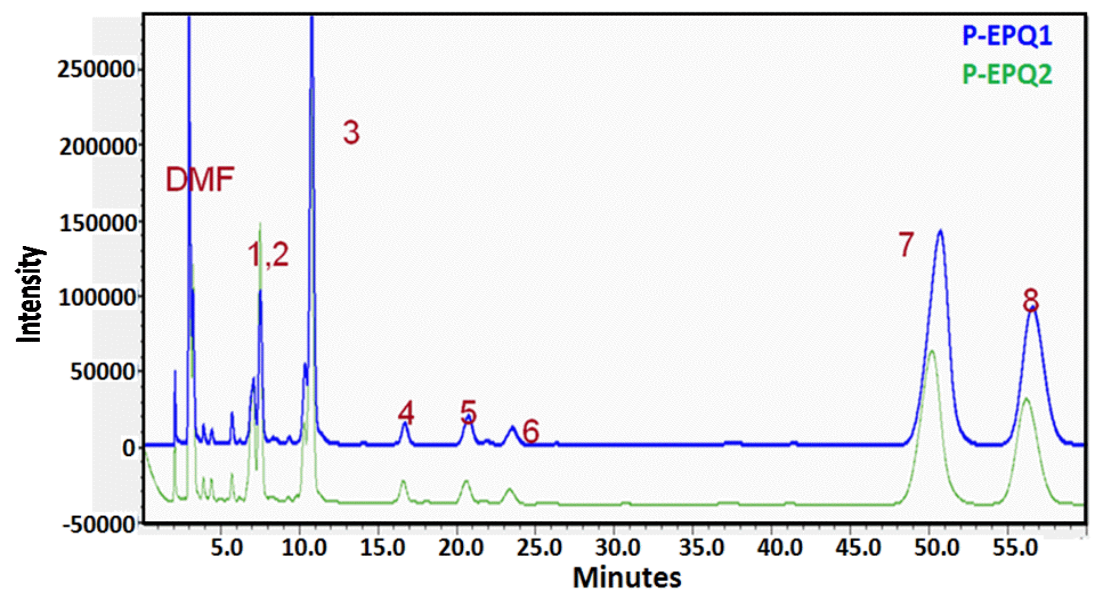

Fig. 3.1 HPLC chromatogram of PEPQ1 and PEPQ2

\begin{tabular}{llll}
\hline & P-EPQ1 & P-EPQ2 \\
Major peak \# & Area counts & Area counts \\
1 & 1801 & 942 \\
2 & 2760 & 1526 \\
3 & 6000 & 6454 \\
$4 *$ (Irgafos 168) & $459(16.1 \%$ of Irgafos $415 \quad(14.6 \%$ of Irgafos \\
5 & $168)$ & $168)$ & \\
6 & 619 & 782 & \\
7 & 443 & 517 & \\
8 & 9619 & 13418 & \\
\hline
\end{tabular}

Table 3.2 Area count of $0.5 \%$ solution of different components of P-PEPQ samples

From Table 3.2, Irgafos 168 present in both PEPQ was almost similar in the range of $14-16 \%$. However, there was significant variation in area count of component 1, component 2, component 7 and component 8 in P-EPQ1 and P-EPQ2 samples. It can be concluded from the above data that both P-EPQ have same number of components but have significantly different composition.

\section{Characterization of commercial BOPP samples}

The MFI and Xylene soluble of the 3 different batches of commercial BOPP grades are summarized in Table 3.3.

\begin{tabular}{lcc}
\hline Sample Detail & $\begin{array}{r}\text { MFI @ 2.16 Kg } \\
\text { g/10 min }\end{array}$ & $\begin{array}{c}\text { Xylene } \\
\text { Soluble } \\
\text { (wt\%) }\end{array}$ \\
\hline BOPP- N & 3.2 & 4.5 \\
BOPP - PEPQ1 & 3.0 & 4.4 \\
BOPP - PEPQ2 & 3.0 & 4.3 \\
\hline Table 3.3 Physico-chemical properties of \\
Polypropylene
\end{tabular}




\begin{tabular}{|c|c|c|c|c|c|}
\hline Sample Detail & AO 1010 & Irgafos 168 & P-EPQ-1 & P-EPQ-2 & DHT-4A \\
\hline & \multicolumn{5}{|c|}{ Concentration in ppm } \\
\hline BOPP- N & 463 & 940 & nil & nil & 261 \\
\hline BOPP - PEPQ1 & 593 & nil & 900 & nil & 225 \\
\hline BOPP - PEPQ2 & 488 & nil & nil & 864 & 222 \\
\hline
\end{tabular}

Table 3.4 Additives composition in Polypropylene

As seen from the Table 3.3, there is not much variation in MFI and xylene soluble of the samples taken for the study. The antioxidant and acid scavenger concentration in all the three samples of Polypropylene was determined using HPLC and XRF respectively. The results are summarized in Table 3.4. As mentioned earlier, that composition of both $P$ EPQ1 and P-EPQ2 is different, therefore, different calibration was carried in order to do the quantification of P-EPQ in Polypropylene.

Results indicate the difference in additive package in different Polypropylene samples. BOPP-N contains additive package comprising of primary antioxidant and secondary antioxidant, AO-1010 and Irgafos-168 in the ratio of 1: 2 respectively, the workhorse antioxidants of Polyolefin industry. BOPP-PEPQ1 and BOPP-PEPQ2 contain a different secondary antioxidant namely P-EPQ instead of Irgafos168 at similar concentration ranges. The concentration of AO 1010 and DHT-4A in both samples was comparable.

\section{Melt Flow Rate Studies}

Multiple extrusion studies were carried out to study the efficacy of antioxidant package in polypropylene samples keeping processing conditions constant. As a thumb rule for multiple extrusion studies, the ratio of melt flow index at $2.16 \mathrm{Kg}$ load for $5^{\text {th }}$ pass to $1^{\text {st }}$ pass should not exceed 1.5 at the application temperature. Multiple extrusion studies at $230^{\circ} \mathrm{C}$ (Fig. 3.2a) indicate that there was no significant variation in MFI from $1^{\text {st }}$ to $5^{\text {th }}$ pass for 3 different samples (BOPP-N, BOPP-PEPQ1 and BOPP-PEPQ2). At the higher extrusion temperature of $250^{\circ} \mathrm{C}$ (Fig. 3.2b), variation of MFI at different passes was significant. The MFI ratio of $5^{\text {th }}$ pass to $1^{\text {st }}$ pass is summarized in Table 3.5. BOPP-N has MFI ratio of 1.2 at $250^{\circ} \mathrm{C}$ and BOPP-PEPQ1 and BOPP-PEPQ2 have MFI ratio of 1.03 and 1.02 respectively.

Results show that at extrusion temperature of $230^{\circ} \mathrm{C}$, MFI of all the PP samples was comparable but real distinction could be observed at higher extrusion temperature of $250^{\circ} \mathrm{C}$. However, it is well known that P-EPQ is superior secondary antioxidant than Irgafos 168 and hence gives better thermal stability. BOPPPEPQ1 and BOPP-PEPQ2 samples behaved similarly in terms of their thermal stability in multiple extrusion studies.

\section{Variation of Yellowness Index with different passes}

Slight improvement in yellowness index (YI) was observed at different passes with the samples containing P-EPQ as compared to sample containing Irgafos 168 . At $250^{\circ} \mathrm{C}$ (Fig. 3.3b), the difference between samples containing P-EPQ and sample containing Irgafos 168 is magnified. The yellowness index of BOPP-N sample increased abruptly from -1.9 units to 7.3 units, whereas for the samples containing P-EPQ, yellowness index increases from -1.9 units to 
max -0.2 units. PEPQ2 sample showed better yellowness index retention P-EPQ1 from $1^{\text {st }}$ pass to $5^{\text {th }}$ pass. It can be concluded from the multiple pass study that P-EPQ is better secondary antioxidant than Irgafos 168 in terms of thermal stability and colour retention. Also, both P-EPQ samples provide good thermooxidative stability to Polypropylene maintaining the initial MFI and colour even though they have different concentration of components. Studies were further extended to see the effect of additive package on the surface and optical properties of BOPP film.
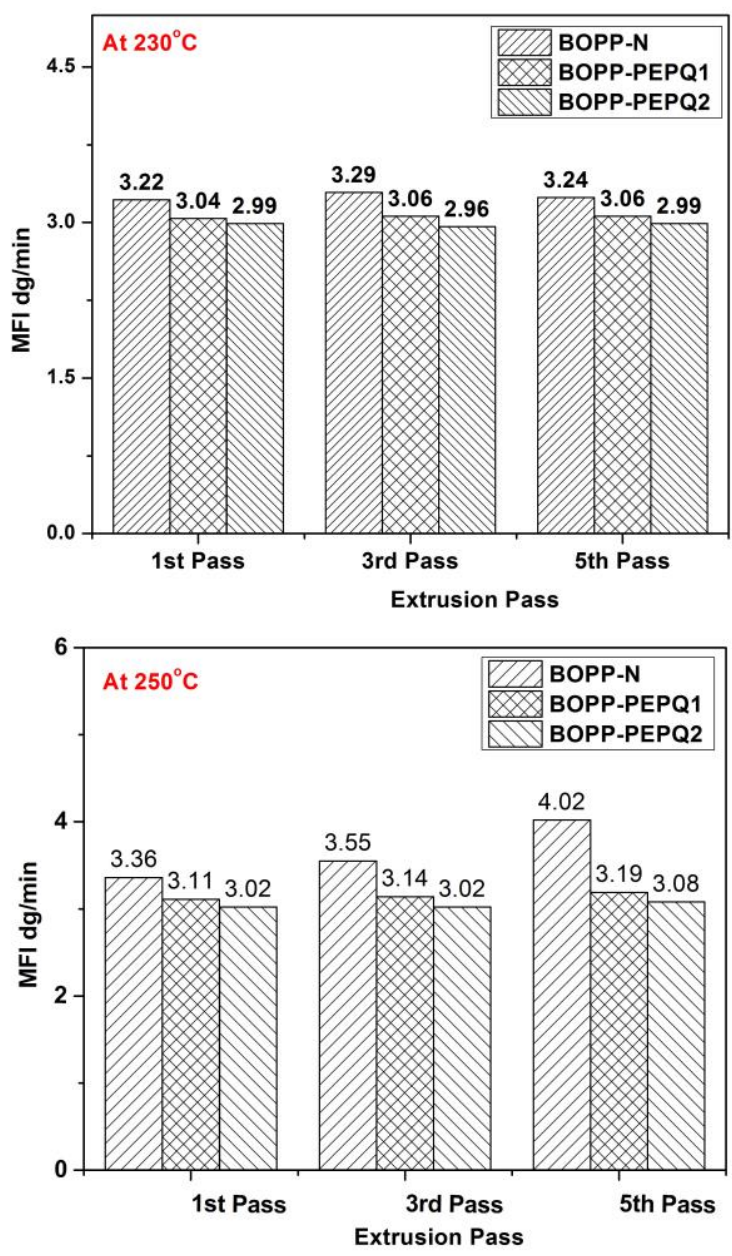

Fig. 3.2 Melt flow rate at different passes at two different temperatures; a) $230^{\circ} \mathrm{C}$; b) $250^{\circ} \mathrm{C}$.

\begin{tabular}{|c|c|c|}
\hline Sample Detail & $\begin{array}{c}\text { MFI Ratio of } \\
5^{\text {th }} / 1^{\text {st }} \text { pass } \\
\text { at } 230^{\circ} \mathrm{C}\end{array}$ & $\begin{array}{c}\text { MFI Ratio of } \\
5^{\text {th }} / 1^{\text {st }} \text { pass } \\
\text { at } 250^{\circ} \mathrm{C}\end{array}$ \\
\hline BOPP- Normal & 1.01 & 1.20 \\
\hline BOPP - PEPQ1 & 1.01 & 1.04 \\
\hline BOPP - PEPQ2 & 1.00 & 1.02 \\
\hline
\end{tabular}

Table 3.5 MFI ratio of $5^{\text {th }}$ passes to $1^{\text {st }}$ passes at $2.16 \mathrm{Kg}$ load
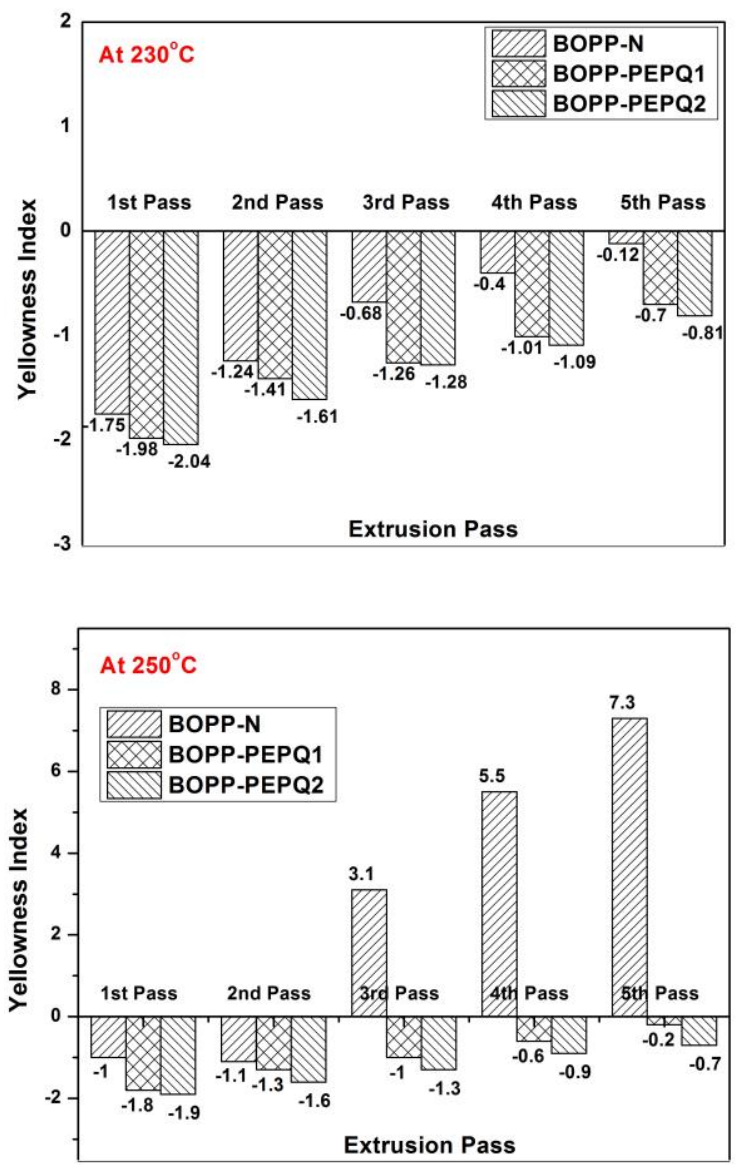

Fig. 3.3 yellowness index at $1^{\text {st }}$ to $5^{\text {th }}$ pass at two different temperatures; a) $230^{\circ} \mathrm{C}$; b) $250^{\circ} \mathrm{C}$.

Effect of P-EPQ on surface and optical properties of BOPP Film

Three layered BOPP films prepared were slitted after 24 hrs of maturation time and the development of colour was observed. Table 3.6 summarizes the optical properties obtained with different secondary antioxidants present in films. 


\begin{tabular}{ll}
\hline \multicolumn{1}{c}{ Sample Detail } & Color \\
\hline BOPP- N & Yellowish \\
BOPP - PEPQ1 & Light yellow \\
BOPP - PEPQ2 & White \\
\hline
\end{tabular}

Table 3.6 colour of the slitted roll of BOPP film

\begin{tabular}{lccccc}
\hline Sample Detail & $\begin{array}{l}\text { Initial } \\
\text { Retention }\end{array}$ & $\begin{array}{l}\text { Dyne } \\
\text { after } 1 \text { month }\end{array}$ & $\begin{array}{l}\text { Dyne } \\
\text { after } 6 \text { months }\end{array}$ & $\begin{array}{l}\text { Retention } \\
\text { mith ICP }\end{array}$ \\
\hline BOPP- N & 46 & $<36$ & $<36$ & Poor \\
BOPP- PEPQ1 & 48 & 47 & 41 & Good \\
BOPP- PEPQ2 & 48 & 46 & 40 & Good \\
\hline
\end{tabular}

Table 3.7 Dyne retention of BOPP films

mettalizable BOPP film grade is dyne retention

The BOPP film prepared with Irgafos 168 gave yellowish colour to the film which is not acceptable in the market whereas film containing P-EPQ showed no or lower yellowish tinge indicating $P E P Q$ as better secondary antioxidant than Irgafos 168. However, in comparison within different $\mathrm{P}-\mathrm{EPQ}$, it was surprising to see that $\mathrm{P}$-EPQ2 gave whitish colour in the slitted role compared to P-EPQ1. These results obtained were contrary to multiple extrusion studies which indicate that both P-EPQ gave almost equivalent thermooxidative and colour stability. From the earlier results, it was analysed and observed that both P-EPQ samples have different composition although the number of components is similar. This difference in the composition of different components of P-EPQ may have led to difference of colour in the final application. BOPP films prepared with P-EPQ2 gave better colour compared to films prepared with PEPQ1. Another major requirement for and compatibility with impact copolymers. In metalized BOPP grade, core layer is BOPP grade and skin layer is a combination of impact polypropylene and anti-block additive.

Metallized biaxially oriented polypropylene (BOPP) films offer excellent gas and water vapor barrier properties, making it of an exceptional value as a barrier packaging film. The metal adhesion to BOPP is normally poor due to its low surface energy, however, pre-treatment of the film surface imparts surface functionality which in turn improves metal adhesion and this surface functionality is measured by dyne retention. As a thumb rule, after 6 months dyne retention of the metalized BOPP film should not be less than 38 units. Lower dyne retention in BOPP film indicates poor compatibility with impact co-polymer polypropylene (ICP). Dyne retention values of BOPP films are in Table 3. 
Dyne retention value of all the three film samples initially was at par with each other. However, a sharp dip in dyne retention value was observed in BOPP film produced with Irgafos 168. Lower value indicates poor compatibility of core layer (homopolymer) and skin layer (impact copolymer). Dyne retention value even after six months was found to be in the acceptable range for the BOPP film having $P$-EPQ, values were found to be higher (46) than the required (36) limit. The reason of poor dyne retention and yellowish colour of the BOPP film produced with Irgafos 168 vis-à-vis P-EPQ could be due to following:

- Irgafos 168 has higher melting temperature and relatively poor miscibility with Polyproylene matrix while P-EPQ has lower melting temperature and has good miscibility within polymer matrix. Since the line temperature, line speed and shear in the BOPP manufacturing process is very demanding, $P$-EPQ gives better thermooxidative stability than Irgafos 168.

BOPP film if not properly stabilized may result in degraded product (lower molecular weight species) which migrate to the surface of the film after certain time period and affect the film dyne retention property and also lowers the compatibility with impact polypropylene. P-EPQ being better secondary antioxidant, if added to polypropylene controls the degradation in a much efficient way compared to AO-168 and relatively less amount of low molecular weight species will be formed compared to Irgafos 168 and hence better properties.

\section{CONCLUSION}

In the present paper, an HPLC based method was established to separate different components of P-EPQ. Analysis of two P-EPQ showed different composition of similar components. BOPP samples containing PEPQ1 and PEPQ2 showed lower change in MFI and yellowness index value than BOPP-N. Apart from its primary function of protecting degradation of polypropylene, this paper also demonstrates that P-EPQ also imparts other functions like improvement in dyne retention and compatibility with impact polypropylene. Study also prove the hypothesis "degradation always leads to formation of low molecular weight species. Addition of P-EPQ in the BOPP film will curtain the amount of low molecular weight species as compared to Irgafos 168 and hence lower a migration of these species to the surface of film will lead to better dyne retention efficiency and compatibility with impact copolymer of polypropylene.

\section{EXPERIMENTAL}

\section{Material}

Three different lots of commercial homopolymer polypropylene resin of IndianOil Corporation Ltd. (MFI 3g/10min and xylene solubles of 4.5 wt\%) was used. Two different PEPQ samples were designated as PEPQ-1 and PEPQ-2. Polypropylene samples were designated as BOPP-N (with Irgafos 168), BOPP$P E P Q 1$ and BOPP-PEPQ2 corresponding to PEPQ1 and P-EPQ2 respectively.

\section{Methods}

Melt Flow Index (MFI): Melt flow index of polypropylene granules was determined at 2.16 $\mathrm{Kg}$ load and $230^{\circ} \mathrm{C}$ on Goetffert MI-4 MFI machine as per ASTM D1238.

Xylene Soluble (XS): Xylene Soluble of polypropylene granules was determined gravimetrically as per ASTM D5492.

Yellowness Index (YI): Yellowness Index of polypropylene granules was determined as per ASTM E313 on M/s HuneterLab Lab Scan XE instrument.

Dyne Retention Studies: Dyne retention of the BOPP films was determined as per ASTM D2578-04a.

Extraction of Additives: The polypropylene granules $(3 \mathrm{~mm})$ were grounded to powder to 300-500 micron size in Retsch Cryo Mill under 
liquid nitrogen. $2 \mathrm{~g}$ of polypropylene powder was taken into a extraction vessel having $25 \mathrm{~mL}$ of solvent (mixture of acetone: cyclohexane 70:30). Extraction was carried out in CEM International microwave extraction machine at a temperature of $125^{\circ} \mathrm{C}$.

HPLC for additive quantification: The additive quantification was carried in ThermoFisher reverse phase HPLC, using a gradient of water, isopropanol and acetonitrile at a temperature of $50^{\circ} \mathrm{C}$

HPLC for P-EPQ analyses: The High-performance liquid chromatography analysis was carried on Shimadzu machine (LC-2010 CHT). Machine comprises of a degasser unit (DGU-20A) for extracting any dissolved air from the solvents, quaternary pump (LC-30AD) for isocratic and gradient solvent program, an auto sampler (SIL30AC) for sample injection, column oven (CTO20AC) to maintain the temperature and UVDAD (SPD-M20A) detector. Method developed for analysis of PEP-Q is

\section{Optimized Analytical Conditions}

- Stationary phase: C-18 Column (Eurospher: 5u, 250X4.6mm)

- Mobile phase: HPLC grade Methanol

- Reference Standard solution was prepared in Methanol-Acetonitrile taken in 9:1 ratio.

- The two samples were first dissolved in DMF at $1 \%(w / V)$ conc. level. The solutions were then diluted with equal volume of methanol.

- Sample injection: 10 ul

- Detector: Photo Diode Array (PDA) 200$400 \mathrm{~nm}$; monitored at $254 \mathrm{~nm}$.

$X R F$ : The quantification of acid scavenger and PEPQ was carried using XRF.

Multiple Extrusion Studies: Multiple extrusion studies were carried in Haake single screw extruder having L/D of 24 and screw speed of $80 \mathrm{rpm}$. Polypropylene was extruded five times. The multiple extrusion studies were carried at two different temperature $230^{\circ} \mathrm{C}$ and $250^{\circ} \mathrm{C}$.
The melt flow rate (MFR) and yellowness index (YI) was determined of each pass. Since BOPP films are produced at higher temperature therefore extrusion study was carried out at higher temperatures.

BOPP films: Three layered tape textile BOPP film having average thickness of 23 micron was prepared on $8.7 \mathrm{~m}$ wide Bruckener line having output of $5.5 \mathrm{~m} / \mathrm{hr}$ using three different polypropylene samples (BOPP-N, BOPP-PEPQ1 and BOPP-PEPQ2). Processing was carried out at barrel zone temperatures from $230^{\circ} \mathrm{C}-255^{\circ} \mathrm{C}$ and die zone temperature from $255^{\circ} \mathrm{C}-260^{\circ} \mathrm{C}$. Stretching Ratios in machine direction was 4.83 and transverse direction was 9.65. All three layers of BOPP films comprised 3MFI PP homopolymer.

\section{REFERENCES}

Aniunoh, K. and Harrison, GM. 2010,' The processing of polypropylene cast films. I. Impact of material properties and processing conditions on film formation', Polymer Engg. and Sc., vol. 50, no. 6, pp.1151-1160.

Blythe AR, et al. 1978, 'Surface modification of polyethylene by electrical-discharge treatment and the mechanism of auto-adhesion', Polymer, vol. 19, no. 11, pp.1273-1278. (1978).

Bruheim, I., Molander, P., Lundanes, E. and Greibrokk T. 2000, 'Temperature-Programmed Packed Capillary Liquid Chromatography Coupled to Fourier-Transform Infrared Spectroscopy', J. High Resol. Chromatography, vol. 23, no. 9, pp.525-530.

Decker, W., Pirzada, S., Michael, M., Yializis, A. 2000, 43rd Annual Technical Conference Proceedings.

Dias, P., Hiltner, A., Baer, E., Van Dun, J., Chen, H.Y., Chum, S.P. 2006, Annual Tech Conference, Society of Plastic Engineers, vol. 64, pp.2660.

Krohnke, C. and Werner, F. 2001, 'Stabilizers for Polyolefins', Rapra Review Reports, vol. 11, no. 21.

Lupke, T., Dunger, S., Sanze, J., Radusch, H. 2004, 'Sequential biaxial drawing of polypropylene films', Polymer, vol. 45, no. 20, pp.6861-6872.

Markgraf, M.P. 1993, 'Corona Treatment: An Adhesion Promoter for UV/EB Converting', Rad Tech Report, vol. 7, no. 5. 
Goel et al. 2018, European Journal of Sciences (EJS), vol. 1, no. 1, pp.1-9, DOI: 10.29198/ejs1801

Markgraf, D.M. 1998, 'Corona Treatment - An overview', Enercon Industries Corp.

Phillips, R.A., Nguyen, T. 2001, 'Structure, processing, morphology, and property relationships of biaxially drawn Ziegler-Natta/metallocene isotactic polypropylene film'. J. Appl Poly Sc., vol. 80, no. 13 , pp.2400-2415.

Rettenberger, S., Capt, L., Munstedt, H., Stopperka, K., Sanze, J. 2002, 'Uniaxial deformation behavior of different polypropylene cast films at temperatures near the melting point', J. Rheol Acta., vol. 41, no. 4, pp.332-336.

Tolinski, M. 2009, Additives for Polyolefin's, first edition, Elsevier Inc. 